\title{
Regional Well-to-Wheel Carbon, Energy, and Water Footprint Analysis of Electric Vehicles
}

\author{
Nuri Cihat Onat'Murat Kucukvar, and Omer Tatari
}

\begin{abstract}
Adoption of alternative vehicle technologies such as electric vehicles (EVs), plug-in hybrid electric vehicles (PHEVs), and hybrid electric vehicles (HEVs) have the potential of reducing some of the environmental impacts and reducing oil-dependency of the U.S transportation sector. However, this potential depends on the regional driving patterns and the source of the electricity generation to power PHEVs and EVs. In this study, state-specific electricity generation mix scenarios and driving patterns in Alabama, Florida, and Hawaii are considered to calculate regional impacts associated with alternative vehicle technologies (HEVs, PHEVs, EVs) compared to internal combustion vehicles (ICVs). Three electricity generation mix scenario are evaluated, which are namely; average electricity generation mix, marginal electricity generation mix, and $100 \%$ solar electricity generation mix. Well-to-wheel carbon, energy, and water footprint of these vehicles are quantified for each state and potential environmental reductions are evaluated. According to comparative evaluation for the proposed scenarios, shifting to low carbon, energy, and water intensive electricity generation mix by utilization of solar energy is crucial to achieve environmental friendly transportation in the U.S.
\end{abstract}

Index Terms - carbon, energy, water, electric vehicles.

\section{INTRODUCTION}

Transportation sector is one of the largest source of Greenhouse gas (GHG) emissions and energy consumption in the United States. Energy consumption and GHG emission share of the transportation sector is approximately $28 \%$ of the U.S. total [1,2]. Adoption of alternative vehicle technologies to reduce these environmental impacts has been a growing interest in the literature and industry $[3,4]$. In addition to environmental issues, concerns associated with rising oil prices and national energy security increased the need for sustainable and more efficient transportation systems in the U.S. The amount of petroleum consumed by the transportation sector is significantly higher than the total U.S. petroleum production (about 141\% of the annual production). Light-duty vehicles consume about $63 \%$ of this

N.C. Onat is with the Qatar Transportation and Traffic Safety Center, Qatar University, Doha, Qatar (e-mail: onat@qu.edu.qa)

M. Kucukvar is with the Department of Industrial and Mechanical Engineering, Qatar University, Doha, Qatar

O. Tatari is with the Department of Civil, Environmental and Construction Engineering, University of Central Florida, FL, USA. immense amount and they account for 59\% of the total energy consumption in the U.S. transportation sector [5]. Light-duty vehicles (LDVs) compromise about $85 \%$ of the passenger miles travelled in the United States and it is a rapidly growing transportation mode in the world as well as in the developed countries [6,7].

Adoption of alternative vehicle technologies such as electric vehicles (EVs), plug-in hybrid electric vehicles (PHEVs), and hybrid electric vehicles (HEVs) have the potential of reducing some of the environmental impacts and reduce oil-dependency of the U.S transportation sector [8-12]. However, this potential depends on the regional driving patterns and the source of the electricity generation to power PHEVs and EVs $[13,14]$. For instance, the electricity generation mix to power an EV might come from either a carbon-intensive source such as coal or a lowcarbon source mix with high share of renewable energy such as solar power [15]. Similarly, the water withdrawal, energy use, and other environmental impacts might vary significantly based on the electricity generating mix [1618]. Among the alternative vehicle technologies mentioned above, PHEVs have both an electric and an internal combustion engine. The electric motor is powered by a high capacity battery that is mostly charged from the grid. So, they are capable to displace some of the petroleum consumption with electric power. The portion of the distance that can be powered by electricity depends on several important factors such as all-electric range (AER), driving distance, and driving conditions [19]. AER is defined as the total miles can be driven, after the battery is fully charged, in electric mode (engine-off) before the engine turns on for the first time [20].

In this study, driving patterns in Alabama (AL), Florida (FL), and Hawaii (HI) are considered for various AER options of PHEVs (10, 20,30, and 40) to calculate regional impacts associated with alternative vehicle technologies compared to internal combustion vehicles (ICVs). The driving patterns determine what portion of the vehicle miles travelled (VMT) can be powered by electricity for various ranges of PHEVs. For instance, vehicles travelled less than 30 miles compromise the approximately $63 \%$ of the daily VMT in the U.S. [21]. This percentage can vary from state to state and hence, associated environmental impacts might be significantly different. In this regard, AL, FL, and HI were selected to evaluate how these spatial variations influence the impacts at state level. Furthermore, comparisons between various vehicle options allows a better understanding about how state-level vehicle 
preference can be different based on state-specific electricity generation profiles and driving patterns.

\section{A. Background and Literature Review}

The A comprehensive literature review is undertaken to show the main trend in the literature in the terms of assessed resource consumption and environmental impact categories. In total, 21 peer reviewed well-to-wheel (WTW) studies were evaluated and benchmarked. Although there are wide range of studies assessing environmental impacts stemming from operation phase of the alternative vehicle technologies, majority of these studies (35 out of 36) focused on Global Warming Potential (GWP). Of the 36 WTW studies, 21 of studies assessed the energy consumption in addition to GWP, whereas only 4 study included water withdrawals, in which carbon and energy perspectives were not taken into account. It is important to note that adoption of PHEVs or EVs will increase the water consumption due to the high water withdrawals from power generation sector in the U.S., which is primarily for cooling purposes in power plants. Coal power plants are responsible for approximately $40 \%$ of the annual water withdrawal in the U.S. [22]. Hence, analyzing water withdrawals resulting from adoption of PHEVs and EVs is also important to avoid possible adverse impacts associated with water sources. Also, majority of the studies did not analyze the end-point indicators such as acidification potential (AP), abiotic depletion potential (ADP), and eutrophication potential (EP).
On the other hand, effects of spatial and temporal variations on the GHG emissions and energy consumption of alternative vehicle technologies were investigated by various researchers [19,23,24]. Axen et al. [25] analyzed WTW GHG emissions of PHEVs by taking into account variations in driving distance. Kelly et al. [26] examined the effects of the U.S. driving patterns, battery charging scenarios, and demographic variations on GHG emissions from use phase of PHEVs. Raykin et al. [19] conducted a WTW analysis of PHEVs to show how driving distance and conditions influence the GHG emissions under various electricity generation mix scenarios. Elgowainy et. al. [27] highlight that potential reduction in energy use and GHG emissions for use PHEVs are higher as the AER increased and renewable energy sources are utilized. Considering that inclusion of spatial and temporal variations are essential to assess environmental impacts associated with operation phase of alternative vehicle technologies, state-specific electricity generation mixes and driving patterns for Alabama, Florida, and Hawaii are taken into consideration. This study aims to show carbon, energy, and water footprints of alternative vehicle technologies for the abovementioned states. The potential reductions on these environmental impact categories are also quantified by making comparisons between the alternative vehicle technologies.

TABLE I

ENVIRONMENTAL IMPACTS AND RESOURCE CATEGORIES INCLUDED IN THE WTW STUDIES

\begin{tabular}{|c|c|c|c|c|c|c|c|c|c|c|c|c|}
\hline \multirow[b]{2}{*}{ \#ref. } & \multirow[b]{2}{*}{ Author(s) } & \multirow[b]{2}{*}{ 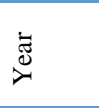 } & \multicolumn{10}{|c|}{ Environmental impact and resource category } \\
\hline & & & $\begin{array}{l}\text { GHG/ } \\
\text { GWP }\end{array}$ & Energy & Water & AP & ADP & EP & HTP & ET & ODP & POFP \\
\hline$[28]$ & Hackney and Neufville & 2001 & $\checkmark$ & $\checkmark$ & & & & & & & & \\
\hline [29] & Plotkin et al. & 2002 & $\checkmark$ & $\checkmark$ & & & & & & & & \\
\hline [30] & Lave and Maclean & 2002 & $\checkmark$ & & & & & & & & & \\
\hline [31] & Daniel and Rosen & 2002 & $\checkmark$ & $\checkmark$ & & & & & & & & \\
\hline [32] & Van Mierlo et al. & 2004 & $\checkmark$ & & & $\checkmark$ & & & $\checkmark$ & & & \\
\hline [33] & Brinkman et al. & 2005 & $\checkmark$ & $\checkmark$ & & & & & & & & \\
\hline [34] & Mohamadabadi et al. & 2009 & $\checkmark$ & $\checkmark$ & & & & & & & & \\
\hline [35] & Stephan and Sullivan & 2008 & $\checkmark$ & $\checkmark$ & & & & & & & & \\
\hline [36] & Kintner-Meyer et al. & 2007 & $\checkmark$ & & & & & & & & & \\
\hline [37] & Fontaras et al. & 2008 & $\checkmark$ & & & & & & & & & \\
\hline [38] & Letendre et al. & 2008 & $\checkmark$ & & & & & & & & & \\
\hline [39] & King and Webber & 2008 & & & $\checkmark$ & & & & & & & \\
\hline [40] & Elgowainy et al. & 2010 & $\checkmark$ & $\checkmark$ & & & & & & & & \\
\hline [41] & Huo et al. & 2010 & $\checkmark$ & $\checkmark$ & & & & & & & & \\
\hline [25] & Axsen et al. & 2011 & $\checkmark$ & & & & & & & & & \\
\hline$[42]$ & Bartolozzi et al. & 2012 & $\checkmark$ & & & $\checkmark$ & $\checkmark$ & $\checkmark$ & $\checkmark$ & $\checkmark$ & $\checkmark$ & $\checkmark$ \\
\hline [43] & Thomas et al. & 2012 & $\checkmark$ & & & & & & & & & \\
\hline [19] & Raykin et al. & 2012 & $\checkmark$ & $\checkmark$ & & & & & & & & \\
\hline [26] & Kelly et al. & 2012 & $\checkmark$ & $\checkmark$ & & & & & & & & \\
\hline$[24]$ & Marshall et al. & 2013 & $\checkmark$ & $\checkmark$ & & & & & & & & \\
\hline [44] & Faria et al. & 2013 & $\checkmark$ & $\checkmark$ & & & & & & & & \\
\hline$[45]$ & Hawkins et al. & 2013 & $\checkmark$ & & & $\checkmark$ & $\checkmark$ & $\checkmark$ & $\checkmark$ & $\checkmark$ & $\checkmark$ & $\checkmark$ \\
\hline [46] & Onat et al. & 2014 & $\checkmark$ & $\checkmark$ & $\checkmark$ & & & & & & & \\
\hline$[47]$ & Messagie et al. & 2014 & $\checkmark$ & $\checkmark$ & & $\checkmark$ & & & & & & \\
\hline$[15]$ & Onat et al. & 2015 & $\checkmark$ & $\checkmark$ & & & & & & & & \\
\hline [48] & Bauer et al. & 2015 & $\checkmark$ & & & $\checkmark$ & & & $\checkmark$ & & & $\checkmark$ \\
\hline [5] & Onat N. C. & 2015 & $\checkmark$ & $\checkmark$ & & & & & & & & \\
\hline
\end{tabular}




\begin{tabular}{|l|l|r|l|l|l|l|l|l|l|l|l|l|}
\hline$[49]$ & Huo et al. & 2015 & $\checkmark$ & & & & & & & & & $\checkmark$ \\
\hline$[12]$ & Onat N. C. & 2015 & $\checkmark$ & $\checkmark$ & & & & & & & & $\checkmark$ \\
\hline$[50]$ & Orsi et al. & 2016 & $\checkmark$ & & & & & & & & & \\
\hline$[51]$ & Onat et al. & 2016 & $\checkmark$ & $\checkmark$ & $\checkmark$ & & & & & & & \\
\hline$[52]$ & Zhao et al. & 2016 & $\checkmark$ & $\checkmark$ & & & & & & & & \\
\hline$[53]$ & Onat et al. & 2016 & $\checkmark$ & $\checkmark$ & & & & & & & & \\
\hline$[10]$ & Onat et al. & 2016 & $\checkmark$ & & & & & & & & & $\checkmark$ \\
\hline$[54]$ & Bicer and Dincer & 2017 & $\checkmark$ & & & & & & $\checkmark$ & & $\checkmark$ & \\
\hline$[55]$ & Onat et al. & 2017 & $\checkmark$ & $\checkmark$ & $\checkmark$ & & & & & & & \\
\hline
\end{tabular}

\section{Methodology}

WTW analysis is a specific type of life cycle assessment used for transportation fuels to power the vehicles. There are two main stages of WTW analysis, which are "well-totank (WTT)" and "tank-to-well (TTW)". The former refers to upstream impacts including raw material extraction, fuel production, and fuel delivery, while the letter is used for direct impacts such as tail pipe emissions during vehicle operation [27]. WTT analysis are conducted by using the data from the Economic Input-Output Life Cycle Assessment tool [56] for the petroleum production and the U.S. Life Cycle Inventory [57], the GREET 2.7 vehicle cycle model [58], and previous studies [43,59-62] for the upstream impacts from electricity generation. TTW impacts are calculated through using data from the U.S. Environmental Protection Agency (EPA) for direct energy consumption and GHG emissions [63,64]. There is no direct water withdrawal for the operation phase of the vehicles except the car wash and therefore, TTW water withdrawal impacts are neglected. In this study, seven vehicle types, ICVs, HEVs, PHEV10, PHE20, PHEV30, PHEV40, and EVs, are evaluated and compared in the terms of carbon, energy, and water footprints for AL, FL, and HI. The useful life time for all vehicles is assumed to be 150,000 miles. 150,000 miles $(240,000 \mathrm{~km})$ is one of the most common assumption made for the economic lifetime of a vehicle in both GREET vehicle cycle model and a good number of studies in the literature [65-67]. In addition to state-specific driving patterns obtained from the National Travel Household Survey [68], three different electricity generation scenarios are considered to account for the variability in power generation source. The electricity generation scenarios are based on the average electricity generation mix, marginal electricity generation mix, and fully solar electricity generation mix. In the first scenario, the average electricity generation mixes given by eGRID 2016 database were utilized to calculate carbon, energy, and water factors per $\mathrm{kWh}$ of electricity generation [69]. Similarly, these factors are quantified for marginal electricity generation scenario for 2020. The data for marginal electricity mixes are obtained from National Oak Ridge Laboratory's estimations and literature [43,59]. Third scenario proposes widespread use of solar charging stations and assumes a $100 \%$ solar energy to power EVs and PHEVs. The life cycle emissions and energy consumption of a typical solar charging station are derived from Engholm et al.[70], We used their life cycle inventory used to obtain the technical details of a typical solar charging station. They calculated the LCA impacts of a solar charging station, which consists of a steel frame standing on a concrete ground. The station has two solar PV modules; each has 7$\mathrm{m}^{2}$ surface area and mounted on the top of the steel frame. Additionally, the system contains several electronic components such as an inverter, cables, and transformers. The sun-hour data is scaled for Alabama, Florida, and Hawaii using sun-hour of state to capture the regional variations. The GHG emissions are reported based on 100 years of time horizon GWP values provided by the International Panel on Climate Change [71]. The functional unit of this analysis is 1 mile of vehicle travel.

\section{A. Well-to-Tank Calculations}

WTT analysis is conducted for both gasoline and electricity supply. Environmental impacts associated with gasoline supply are calculated with EIO-LCA tool by using NAICS sector 324110, Petroleum Refineries. The EIO-LCA model consists of identical sectors and the monetary transactions among those sectors, which constitute the whole U.S. economy. As the EIO-LCA model cover entire economy, it is capable to capture the supply chain related activities including extraction of raw materials, processing, and transportation [72,73]. Supply-chain linked analysis provide a more comprehensive assessment and accounting the impacts associated with upstream activities [74,75]. Input-output based models provides this strength and provide a comprehensive assessment approach [76-78]. The producer price (\$) for a gallon of petroleum is an input to calculate a set of environmental impacts including carbon, energy, and water footprints. For more detailed information about the EIO-LCA tool please see the reference [56]. Gasoline is consumed by ICVs, HEVs, and PHEVs and the impacts associated with each vehicle type are quantified by determining how much gasoline they consume per VMT. The fuel economy (FE) of ICV and HEV are assumed to be 30 and 50 miles per gallon $(\mathrm{mpg})$, whereas the FE for PHEVs is assumed to be $50 \mathrm{mpg}$ in gasoline mode and 0.29 $\mathrm{kWh} /$ mile in electric mode. Also, FE for EV is assumed to be $0.30 \mathrm{kWh} / \mathrm{mile}$, which is similar to that Nissan Leaf. Although these vehicles are generic, the fuel economy values are relevant to their counterparts available in the market except the PHEV20, PHEV30 and PHEV40 [7982]. The highest AER available in the market is Chevrolet Volt whose AER is 38 mile and the fuel economy value for gasoline more less around 32 miles per gallon (mpg). So, the vehicles PHEV20, PHEV30 and PHEV40 are assumed to an improved version of the plug-in Prius whose fuel economy values are similar to the PHEV10 in this analysis. 
The electricity required to travel a mile includes regenerative braking benefits and efficiency losses in the battery, charger, and electric motor. Additionally, the transmission and distribution losses for each region that covers the corresponding states are added when calculating WTT impacts. The transmission losses are $5.82 \%$ for both FL and AL, and $7.81 \%$ for HI [69].

After calculating the gasoline amount required to travel 1 mile for each vehicle, the producer price for each amount is determined and entered the EIO-LCA model. The producer price for $1 \mathrm{gal}$ of gasoline was $\$ 0.76$ in 2002 [65]. Upstream GHG emissions, energy consumption, and water withdrawals to produce 1 gal of gasoline are calculated as $2120.4 \mathrm{gCO}_{2}$-eq., 24.1 MJ, and 7.15 gallons of water. By using these amounts the impacts associated with gasoline supply can be calculated by multiplying the amount of gasoline required to travel 1 mile with the associated impact factor (carbon, energy, or water footprint of producing 1 gal. of gasoline).

Electricity supply is the second important component of WTT analysis and it is the main source of the regional variations owing to different electricity generation mixes of the states. Each energy source utilized to generate electricity has different GHG emission, energy consumption, and water withdrawal impact. Table II indicates these values for each energy source type. The GHG emission factors are obtained from the U.S. Life Cycle Inventory Database [57], which contains both upstream and downstream of power generation process. Energy consumption factors are collected from GREET 2.7 vehicle cycle model [58]. Water withdrawals for biomass and residual fuel oil are taken from Gerbens-Leenes et al. [61]. For the hydropower, average value in the U.S. were used and data is obtained from World Energy Outlook [60].

TABLE II

IMPACT FACTORS OF ELECTRICITY GENERATION BY ENERGY SOURCE

\begin{tabular}{|c|c|c|c|c|c|}
\hline \multirow[b]{2}{*}{$\begin{array}{c}\text { Electricity } \\
\text { Generation Source }\end{array}$} & \multirow{2}{*}{$\begin{array}{c}\mathrm{GHG} \\
\text { emissions } \\
\left(\mathrm{gCO}_{2^{-}}\right. \\
\text {eq/kWh })\end{array}$} & \multicolumn{3}{|c|}{$\begin{array}{c}\text { Energy } \\
(\mathrm{kWh} / \mathrm{kWh})\end{array}$} & \multirow{2}{*}{$\begin{array}{c}\text { Water } \\
\text { Withdr. } \\
\text { (gal/kWh) }\end{array}$} \\
\hline & & Fuel & $\begin{array}{l}\text { Fee } \\
\text { dsto } \\
\text { ck }\end{array}$ & Total & \\
\hline Natural gas & 648.5 & 0.2 & 2.4 & 2.6 & 0.4 \\
\hline Coal & 1042.0 & 0.1 & 3.1 & 3.2 & 0.7 \\
\hline Residual fuel oil & 905.6 & 0.4 & 3.3 & 3.6 & 1.0 \\
\hline Nuclear & 10.9 & 0.1 & 1.1 & 1.1 & 1.2 \\
\hline Hydropower & 8.0 & 0.0 & 0.0 & 0.0 & 68.0 \\
\hline Solar & 60.0 & 0.0 & 0.0 & 0.0 & 0.1 \\
\hline Biomass & 45.7 & 0.2 & 5.1 & 5.4 & 54.2 \\
\hline Wind & 15.0 & 0.0 & 0.0 & 0.0 & 0.0 \\
\hline Geothermal & 122.0 & 0.0 & 0.0 & 0.0 & 0.3 \\
\hline
\end{tabular}

Water withdrawal factors for the rest of the energy sources are collected from Meldrum et al. [62], in which studies quantified the life cycle water consumption and withdrawal factors of various energy types are reviewed. It should be noted that the water withdrawal factors can vary significantly based on the cooling type used in the power plant $[60,62]$.
Table III represents the electricity generation mixes of the states based on the introduced scenarios. As explained previously, Scenario 1 (S1) includes the average electricity generation profiles. It is important to note that the electricity consumption mix and generation mix can vary significantly based on the state electricity imports and exports. The data for export and import values for 2009 is not released yet. Even though these values are available for the former years, the exporter and importer states, and the amount of the interstate trade are not known. This makes the estimation of consumption mixes complicated and uncertain [83]. However, the generation and consumption mix of Hawaii is the same since it does not have grid connection with any of the states in the main land. On the other hand, power plants generally rely on fossil fuels owing to the need for instantaneously meeting the fluctuating electricity demand. Steady supply to meet base electricity load is usually provided through nuclear power and hydroelectric power plants, while natural gas or coal power plants usually provide for some portion of the steady demand and mostly peak demand above the base load. Hence, the additional unsteady demand from use of EVs and PHEVs is more likely to be provided through nonrenewable energy sources. Therefore, regional marginal mixes estimated by the Oak Ridge National Laboratory are also taken into consideration as Scenario 2 (S2). As the solar power is one of the most promising technologies in the terms of energy efficiency and environmental impacts, a fully solar generation mix is offered to highlight its benefits in Scenario 3 (S3).

After defining the electricity generation mixes and impact factors by energy source, state-specific impact factors are calculated by using the values given in Table III. Calculated state-specific impact factors for each scenario and each impact category are presented in the same table. As the impacts per $\mathrm{kWh}$ of electricity generation in each state are determined, the WTT impacts from each vehicle type can be calculated by multiplying the electricity required from grid to travel 1 mile (including the T\&D losses) with the factors given in Table III, depending on the scenario and state combinations. 
TABLE III

STATE SPECIFIC ELECTRICITY GENERATION MiXES OF THE STATES AND IMPACT FACTORS PER KWH OF ELECTRICITY GENERATION FOR EACH SCENARIOS $(\mathrm{S} 1, \mathrm{~S} 2, \mathrm{~S} 3)$

\begin{tabular}{|l|c|c|c|c|c|c|c|c|c|}
\hline \multirow{2}{*}{ Electricity Gen. Source } & \multicolumn{3}{|c|}{ Alabama } & \multicolumn{3}{c|}{ Florida } & \multicolumn{3}{c|}{ Hawaii } \\
\cline { 2 - 10 } & $\mathrm{S} 1$ & $\mathrm{~S} 2$ & $\mathrm{~S} 3$ & $\mathrm{~S} 1$ & $\mathrm{~S} 2$ & $\mathrm{~S} 3$ & $\mathrm{~S} 1$ & $\mathrm{~S} 2$ & $\mathrm{~S} 3$ \\
\hline Natural gas & $22.1 \%$ & $65.1 \%$ & $0.0 \%$ & $54.3 \%$ & $81.8 \%$ & $0.0 \%$ & $0.0 \%$ & $2.3 \%$ & $0.0 \%$ \\
\hline Coal & $38.8 \%$ & $33.3 \%$ & $0.0 \%$ & $24.8 \%$ & $0.3 \%$ & $0.0 \%$ & $13.6 \%$ & $1.9 \%$ & $0.0 \%$ \\
\hline Residual fuel oil & $0.2 \%$ & $0.1 \%$ & $0.0 \%$ & $4.2 \%$ & $16.5 \%$ & $0.0 \%$ & $75.5 \%$ & $96.8 \%$ & $0.0 \%$ \\
\hline Nuclear & $27.7 \%$ & $0.0 \%$ & $0.0 \%$ & $13.3 \%$ & $0.8 \%$ & $0.0 \%$ & $0.0 \%$ & $0.0 \%$ & $0.0 \%$ \\
\hline Hydro-power & $8.7 \%$ & $0.0 \%$ & $0.0 \%$ & $0.1 \%$ & $0.0 \%$ & $0.0 \%$ & $1.0 \%$ & $0.0 \%$ & $0.0 \%$ \\
\hline Solar & $0.0 \%$ & $1.5 \%$ & $100.0 \%$ & $0.0 \%$ & $0.6 \%$ & $100.0 \%$ & $0.0 \%$ & $0.0 \%$ & $100.0 \%$ \\
\hline Biomass & $2.4 \%$ & $0.0 \%$ & $0.0 \%$ & $1.9 \%$ & $0.0 \%$ & $0.0 \%$ & $2.5 \%$ & $0.0 \%$ & $0.0 \%$ \\
\hline Wind & $0.0 \%$ & $0.0 \%$ & $0.0 \%$ & $0.0 \%$ & $0.0 \%$ & $0.0 \%$ & $2.3 \%$ & $0.0 \%$ & $0.0 \%$ \\
\hline Geothermal & $0.0 \%$ & $0.0 \%$ & $0.0 \%$ & $0.0 \%$ & $0.0 \%$ & $0.0 \%$ & $1.5 \%$ & $0.0 \%$ & $0.0 \%$ \\
\hline $\begin{array}{l}\text { GHG emission factor } \mathrm{gCO} 2- \\
\text { eq/KWh) }\end{array}$ & 553.86 & 770.94 & 72.00 & 650.91 & 683.37 & 72.00 & 828.97 & 911.30 & 72.00 \\
\hline Energy Factor $(\mathrm{kWh} / \mathrm{kWh})$ & 2.25 & 2.75 & 0.11 & 2.60 & 2.75 & 0.11 & 3.32 & 3.65 & 0.11 \\
\hline Water factor $(\mathrm{gal} / \mathrm{kWh})$ & 7.90 & 0.49 & 0.09 & 1.70 & 0.52 & 0.09 & 2.93 & 1.03 & 0.09 \\
\hline
\end{tabular}

\section{B. Tank-to-Wheel Calculations}

TTW impacts are directly associated with the amount of energy (gasoline and electricity) consumed during vehicle travel. Direct electricity consumption values were provided Table II. Additionally, the direct energy consumption factors can be calculated by converting the energy content of the gasoline required to travel 1 mile. The tail pipe emissions resulting from combustion of a gallon of gasoline is 8920 $\mathrm{gCO}_{2}$-eq. and the energy content of a gallon of gasoline is 121.3 MJ. By using the fuel economy (FE) values of each vehicle type except PHEVs, the TTW impacts can be calculated as follows;

(TTW impacts) $)_{\text {carbon or energy }}$

$=(1 / F E) *(\text { impact factor })_{\text {carbon or energy }}$

As the PHEVs are capable to operate in electric and gasoline mode, eq. 1 is not sufficient to calculate its impacts. The driving patterns of each state determine the fraction of gasoline and electricity mode of the total travel. The faction of the electric mode is defined with an indicator named Utility Factor (UF). To calculate state-specific UFs, daily cumulative VMT distribution for each state is constructed, which basically shows that the total VMT amount less than a given distance. The main objective is to estimate what percentage of daily travel can be powered by PHEVs considering their AER features. A longer AER provides a greater share of the VMT in electric mode, which is represented with a higher UF. Table IV shows the estimated UFs for the state and vehicle type combinations. It is assumed that the PHEVs are fully charged once in a day. VMT data for these states are collected from 2009 National Household Travel Survey (NHTS) using the online table design tool available at [68]. According to Table IV, $32.16 \%$ of the VMT in Florida are less than 10 miles, which means use of PHEV10 can displace $32.16 \%$ of the gasoline powered VMT with electricity.
TABLE IV

STATE-SPECIFIC UTILITY FACTORS FOR COMBINATION OF VEHICLE TYPES AND STATES

\begin{tabular}{llll}
\hline $\begin{array}{l}\text { Utility } \\
\text { Factors }\end{array}$ & AL & FL & HI \\
\hline PHEV10 & $25.34 \%$ & $32.16 \%$ & $46.32 \%$ \\
\hline PHEV20 & $44.02 \%$ & $55.58 \%$ & $80.56 \%$ \\
\hline PHEV30 & $59.91 \%$ & $68.92 \%$ & $95.18 \%$ \\
\hline PHEV40 & $72.33 \%$ & $76.06 \%$ & $97.40 \%$ \\
\hline
\end{tabular}

As UFs are determined, the WTW impacts from PHEVs can be calculated as follows;

Impact/mile $=U F^{*}\left[(\mathrm{kWh} /\right.$ mile $) *\left(\right.$ Impact factor $\left.\left.{ }_{\text {power generation }} / \mathrm{kWh}\right)\right]+$ $(1-U F) *[(1 / m p g) *$ (Impact factorgasoline supply and combustion $/ k W h)]$ (2)

Impact factors stated in the Eq. 2 are the accumulation of WTT and TTW impacts, which refers to WTW impact factors. Eq. 2 has two parts; first part represents the impacts from electricity and the second part is where gasoline use related impacts are calculated.

\section{RESULTS}

The results are presented in the following subsections representing each environmental impact category.

\section{A. Carbon Footprint Results}

Fig. 1 outlines the state-specific GHG emission results for each vehicle type under S1, S2, and S3. According to the results, all of the alternative vehicle options perform better than ICV. In S1, EV are the best option for AL only, while PHEV40 and HEV are favored the best options in FL and HI, respectively. Adoption of EVs in AL can reduce GHG emissions about 52\% compared to ICVs. When marginal electricity generation mix taken into account, HEV became the best option for AL and HI, PHEV40 remains as the best option for FL. On the other hand, S3 favors the EVs in all of the states. It should be noted that the number of registered LDVs 
are highest (about 7.7 million) in FL and therefore, it has the largest carbon footprint reduction compared to other states. The highest reduction is observed in S3 and adoption of EVs can reduce $94 \%$ of GHG emissions compared to ICVs.

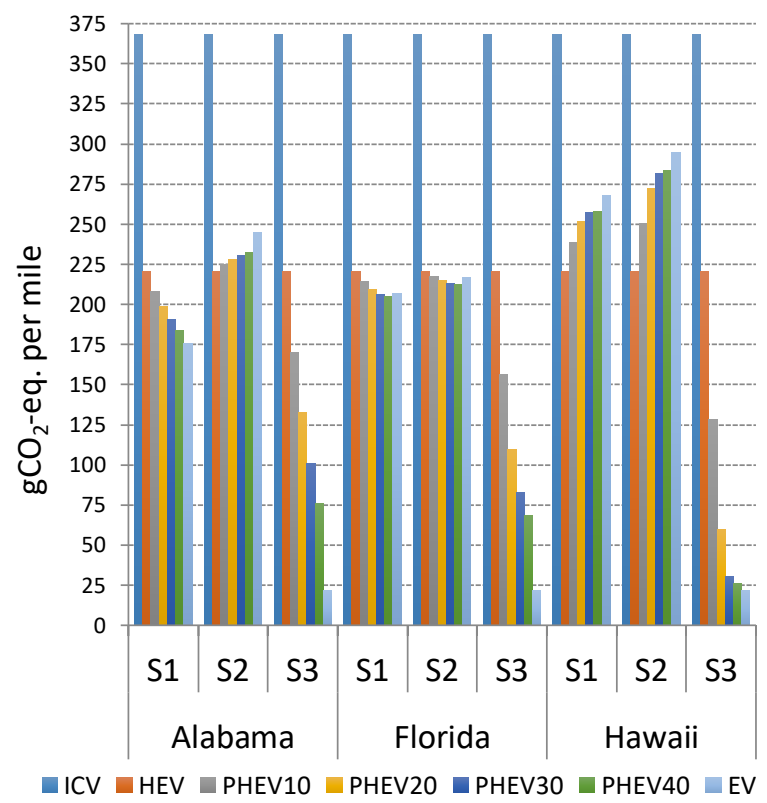

Fig. 1. State-specific WTW GHG emission results

\section{B. Energy Footprint Results}

Fig. 2 indicates the results for energy consumption of each vehicle types. The energy footprint results for S1 and S2 favor the HEVs as a best option in all of the states, which might be stemming from the energy inefficiency of power generation sector in these states. The results for S1 highlight that increase in energy efficiency by utilization of solar power provides much better results for EVs and PHEVs. In the S3, EVs are found to be the best option, while the results for PHEV40 and EVs are very close in $\mathrm{HI}$ due to the fact that almost $98 \%$ of the VMT in HI are less than 40 miles. Hence, performance of PHEV40 is very close to that of the EVs.

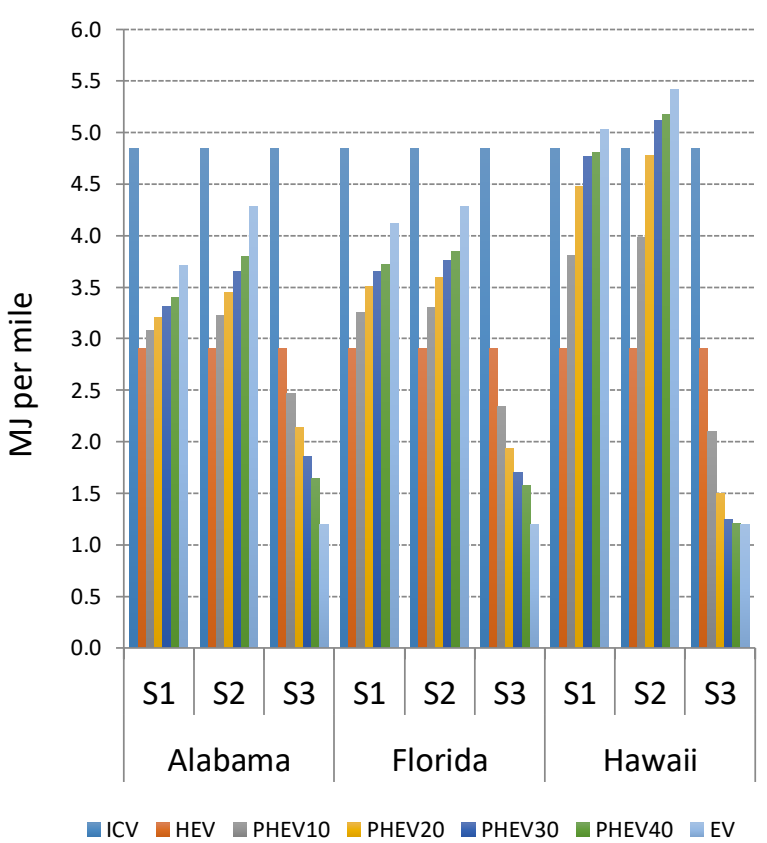

Fig. 2. State-specific WTW Energy consumption results

\section{Water Footprint Results}

Fig. 3 shows state-specific water withdrawal values based on the proposed scenarios for each vehicle type. As can be seen from the figure, the water withdrawal in Alabama is significantly higher than other states due to the reliance on hydropower in S1. On the other hand, the marginal electricity mix scenario decreased the water withdrawals considerably owing to less water reliance in natural gas, which constitute important portion of the marginal electricity mix in $\mathrm{AL}$ and FL. It should be noted that the water withdrawal values can vary significantly based on the cooling technology preference in coal and nuclear power plants. According to deterministic results assuming use of cooling tower as a cooling technology, EVs perform worse than other vehicle types in S1 and S2. As the electrification of the transportation increases in $\mathrm{S} 1$ and $\mathrm{S} 2$, the water withdrawals increase. In contrast, use of solar power in S3 favored EVs and PHEVs due to mush less reliance on water sources in the photovoltaic (PV) technology. 


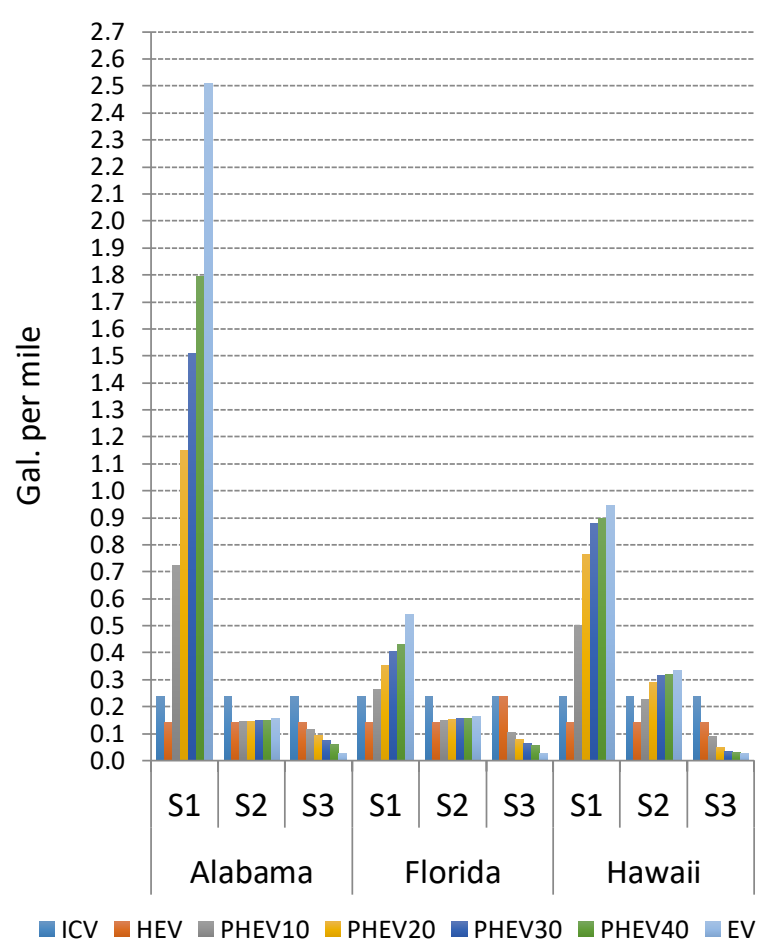

Fig. 3. State-specific WTW water withdrawal results

\section{Conclusions ANd Discussions}

This analysis shows the importance of variances in regional electricity generation mix and driving patterns when quantifying WTW environmental impacts of alternative vehicle technologies. According to comparative evaluation for the proposed scenarios, shifting to low carbon, energy, and water intensive electricity generation mix by utilization of solar energy is crucial to achieve environmental friendly transportation in the U.S. However, the implication of Scenario 3 should be evaluated considering the economic feasibility and market penetration scenarios. Furthermore, the environmental impact reduction achieved by use of alternative vehicle technologies is relative to that of ICVs and it is not certain that the amount of reduction is enough to solve environmental issues such as GWP. Hence, such problems should be studied with dynamic modeling approach which is capable to capture temporal impacts and the interactions among the system variables such as increasing number of vehicles, the current carbon levels in the atmosphere, etc. $[84,85]$. Dynamic models can help to track the impacts across complex systems interacting with each other [86]. Additionally, the sustainable development requires integration of social and economic dimensions in addition to environmental concerns [87-89]. Therefore, future work should integrate three pillars of sustainability.

\section{REFERENCES}

[1] Oak Ridge National Lab. Transportation Energy Data book 2013: Chapter 8 Household Vehicles and Characteristics. http://cta.ornl.gov/data/ chapter8.shtml.

[2] Ercan T, Kucukvar M, Tatari O, and Al-Deek H, "Congestion Relief Based on Intelligent Transportation Systems in Florida," Transp Res Rec
J Transp Res Board 2013;2380:81-9. doi:10.3141/2380-09.

[3] Atılgan, B., Ușaklı, Y. M., Baraçlı, E. M., Onat, N. C., and Kucukvar M, "Investigation of Optimal Charging Locations for Electric Vehicles in Istanbul. Int. Conf. Ind. Eng. Oper. Manag. Bogota, Colomb., Bogota, Colombia," IEOM Society, 2017.

[4] Onat NC, Kucukvar M, Toufani P, and Haider MA, "Carbon Footprint Analysis of Electric Taxis in Istanbul," Int. Conf. Ind. Eng. Oper. Manag. Bogota, Colomb., Bogota, Colombia, IEOM Society, 2017.

[5] Onat NC, "Integrated sustainability assessment framework for the U.S. transportation," University of Central Florida, 2015.

[6] Sager J, Apte JS, Lemoine DM, and Kammen DM, "Reduce growth rate of light-duty vehicle travel to meet 2050 global climate goals," Environ Res Lett, 6:024018. doi:10.1088/1748-9326/6/2/024018, 2011.

[7] Committee for a Study of Potential Energy Savings and, Greenhouse Gas Reductions from Transportation. Policy Options for Reducing Energy Use and Greenhouse Gas Emissions from U.S. Transportation: Special Report 307. Washington DC,: 2011.

[8] Ercan T, Onat NC, Tatari O, and Mathias J-D, "Public transportation adoption requires a paradigm shift in urban development structure," $J$ Clean Prod, 42, 2017. doi:10.1016/j.jclepro.2016.11.109.

[9] Ercan T, Keya N, Onat NC, Tatari O, and Eluru N., "Sustainability Performance Simulation of the U.S. Urban Mobility Policies," Transp Res Board Annu Meet, 2018.

[10] Onat NC, Kucukvar M, and Tatari O., "Uncertainty-embedded dynamic life cycle sustainability assessment framework: An ex-ante perspective on the impacts of alternative vehicle options," Energy, 112:715-28, 2016. doi:10.1016/j.energy.2016.06.129.

[11] Ercan T, Onat NC, and Tatari O., "Investigating carbon footprint reduction potential of public transportation in United States: A system dynamics approach," J Clean Prod, 133, 2016. doi:10.1016/j.jclepro.2016.06.051.

[12] Onat NC., "A macro-level sustainability assessment framework for optimal distribution of alternative passenger vehicles," University of Central Florida, 2015.

[13] Onat NC, Kucukvar M, Tatari O, and Egilmez G., "Integration of system dynamics approach toward deepening and broadening the life cycle sustainability assessment framework: a case for electric vehicles," Int $J$ Life Cycle Assess, 21, 1009-34, 2016. doi:10.1007/s11367-016-1070-4.

[14] Noori M, Zhao Y, Onat NC, Gardner S, and Tatari O., "Light-duty electric vehicles to improve the integrity of the electricity grid through Vehicle-to-Grid technology: Analysis of regional net revenue and emissions savings," Appl Energy, 168:146-58, 2016. doi:10.1016/j.apenergy.2016.01.030.

[15] Onat NC, Kucukvar M, and Tatari O., "Conventional, hybrid, plug-in hybrid or electric vehicles? State-based comparative carbon and energy footprint analysis in the United States," Appl Energy, 150, 2015. doi:10.1016/j.apenergy.2015.04.001.

[16] Shaikh MA, Kucukvar M, Onat NC, Kirkil G., "A framework for water and carbon footprint analysis of national electricity production scenarios," Energy, 139, 2017. doi:10.1016/j.energy.2017.07.124.

[17] Onat NC, Kucukvar M, and Tatari O., "Well-to-wheel water footprints of conventional versus electric vehicles in the United States: A statebased comparative analysis," J Clean Prod, 204:788-802, 2018. doi:10.1016/J.JCLEPRO.2018.09.010.

[18] Kucukvar M, Onat NC, and Haider MA., "Material dependence of national energy development plans: The case for Turkey and United Kingdom," J Clean Prod, 200:490-500, 2018. doi:10.1016/j.jclepro.2018.07.245.

[19] Raykin L, MacLean HL, and Roorda MJ., "Implications of driving patterns on well-to-wheel performance of plug-in hybrid electric vehicles," Environ Sci Technol, 46:6363-70, 2012. doi:10.1021/es203981a.

[20] Markel T., "Plug-In HEV Vehicle Design Options and Expectations," ZEV Technol. Symp. Calif. Air Resour. Board, Sacramento, CA: 2006.

[21] The U.S. Department of Transportation, "National Household SurveySummary of Household Travel Trends," 2009.

[22] Kenny JF, Barber NL, Hutson SS, Linsey KS, Lovelace JK, Maupin M A., "Estimated Use of Water in the United States in 2005," Circ 1344, 52, 2009.

[23] Faria R, Marques P, Moura P, Freire F, Delgado J, and de Almeida AT., "Impact of the electricity mix and use profile in the life-cycle assessment of electric vehicles," Renew Sustain Energy Rev.,24:271-87, 2013. doi:10.1016/j.rser.2013.03.063.

[24] Marshall BM, Kelly JC, Lee T-K, Keoleian GA, and Filipi Z., "Environmental assessment of plug-in hybrid electric vehicles using 
naturalistic drive cycles and vehicle travel patterns: A Michigan case study," Energy Policy, 58:358-70, 2013.

doi:10.1016/j.enpol.2013.03.037.

[25] Axsen J, Kurani KS, McCarthy R, and Yang C., "Plug-in hybrid vehicle GHG impacts in California: Integrating consumer-informed recharge profiles with an electricity-dispatch model," Energy Policy, 39:1617-29, 2011. doi:10.1016/j.enpol.2010.12.038.

[26] Kelly JC, MacDonald JS, and Keoleian GA., "Time-dependent plug-in hybrid electric vehicle charging based on national driving patterns and demographics," Appl Energy, 94:395-405, 2012. doi:10.1016/j.apenergy.2012.02.001

[27] Elgowainy A, and Burnham A., "Well-to-wheels energy use and greenhouse gas emissions of plug-in hybrid electric vehicles," SAE International Journal of Fuels and Lubricants 2, no. 1, 627-644, 2009

[28] Hackney J, de Neufville R., "Life cycle model of alternative fuel vehicles: emissions, energy, and cost trade-offs," Transp Res Part A Policy Pract., 35:243-66, 2001. doi:10.1016/S0965-8564(99)00057-9.

[29] Plotkin S, Santini D, Vyas A, Anderson J, Wang M, Bharathan D., and J. He, "Hybrid electric vehicle technology assessment: methodology, analytical issues, and interim results," No. ANL/ESD/02-2. Argonne National Lab., IL (US), 2002. doi:10.2172/807353.

[30] Lave LB, MacLean HL., "An environmental-economic evaluation of hybrid electric vehicles: Toyota's Prius vs. its conventional internal combustion engine Corolla," Transp Res Part D Transp Environ, 7:155-62, 2002. doi:10.1016/S1361-9209(01)00014-1.

[31] Daniel JJ, and Rosen MA., "Exergetic environmental assessment of life cycle emissions for various automobiles and fuels," Exergy, An Int J, 2:283-94, 2002. doi:10.1016/S1164-0235(02)00076-6.

[32] Van Mierlo J, Timmermans J-M, Maggetto G, Van den Bossche P, Meyer S, Hecq W., Leen Govaerts, and Johan Verlaak, "Environmental rating of vehicles with different alternative fuels and drive trains: a comparison of two approaches," Transp Res Part D Transp Environ, 9:387-399, 2004. doi:10.1016/j.trd.2004.08.005.

[33] Brinkman N, Wang M, Weber T, and Darlington T., "Well-to-wheels analysis of advanced fuel/vehicle systems - a North American study of energy use, greenhouse gas emissions, and criteria pollutant," Argonne Natl Lab, Argonne, 2005.

[34] Mohamadabadi H, Tichkowsky G, Kumar A.,'Development of a multicriteria assessment model for ranking of renewable and non-renewable transportation fuel vehicles," Energy, 34:112-25, 2009. doi:10.1016/j.energy.2008.09.004.

[35] Stephan CH, and Sullivan J., "Environmental and Energy Implications of Plug-In Hybrid-Electric Vehicles, "Environ Sci Technol," 42:118590, 2008. doi:10.1021/es062314d.

[36] Kintner-Meyer M., "Impacts assessment of plug-in hybrid vehicles on electric utilities and regional US power grids," Part 1: Technical analysis. ... Natl Lab 2007.

[37] Fontaras G, Pistikopoulos P, and Samaras Z., "Experimental evaluation of hybrid vehicle fuel economy and pollutant emissions over real-world simulation driving cycles," Atmos Environ, 42:4023-35, 2008. doi:10.1016/j.atmosenv.2008.01.053.

[38] Letendre S, Watts R, Cross M., "Plug-In Hybrid Vehicles and the Vermont Grid: A Scoping Analysis,” Vermont: 2008.

[39] King CW, Webber ME., "The Water Intensity of the Plugged-In Automotive Economy," Environ Sci Technol, 42:4305-11, 2008. doi:10.1021/es0716195.

[40] Elgowainy A, Han J, Poch L, and Wang M., "Well-to-wheels analysis of energy use and greenhouse gas emissions of plug-in hybrid electric vehicles," 2010.

[41] Huo H, Zhang Q, Wang MQ, Streets DG, and He K., "Environmental implication of electric vehicles in China," Environ Sci Technol, 44:4856-61, 2010. doi:10.1021/es100520c.

[42] Bartolozzi I, Rizzi F, Frey M., "Comparison between hydrogen and electric vehicles by life cycle assessment: A case study in Tuscany, Italy," Appl Energy, 101:103-11, 2013 doi:10.1016/j.apenergy.2012.03.021

[43] Thomas S., "US marginal electricity grid mixes and EV greenhouse gas emissions," Int J Hydrogen Energy, 37:19231-40, 2012 doi:10.1016/j.ijhydene.2012.09.146.

[44] Faria R, Moura P, Delgado J, and de Almeida AT., "A sustainability assessment of electric vehicles as a personal mobility system," Energy Convers Manag, 61:19-30, 2012. doi:10.1016/j.enconman.2012.02.023.

[45] Hawkins TR, Singh B, Majeau-Bettez G, and Strømman AH., "Comparative Environmental Life Cycle Assessment of Conventional and Electric Vehicles,” J Ind Ecol, 17:53-64, 2013. doi:10.1111/j.1530- 9290.2012.00532.x

[46] Onat NC, Kucukvar M, and Tatari O., "Towards Life Cycle Sustainability Assessment of Alternative Passenger Vehicles," Sustainability, 6:9305-42, 2014. doi:10.3390/su6129305.

[47] Messagie M, Boureima F-S, Coosemans T, Macharis C, and Mierlo J., "A Range-Based Vehicle Life Cycle Assessment Incorporating Variability in the Environmental Assessment of Different Vehicle Technologies and Fuels," Energies, 7:1467-82, 2014. doi:10.3390/en7031467.

[48] Bauer C, Hofer J, Althaus H-J, and Del Duce A., and Simons A., "The environmental performance of current and future passenger vehicles: Life cycle assessment based on a novel scenario analysis framework," Appl Energy, 157:871-83, 2015. doi:10.1016/J.APENERGY.2015.01.019.

[49] Huo H, Cai H, Zhang Q, Liu F, and He K., "Life-cycle assessment of greenhouse gas and air emissions of electric vehicles: A comparison between China and the U.S.," Atmos Environ, 108:107-16, 2015. doi:10.1016/j.atmosenv.2015.02.073.

[50] Orsi F, Muratori M, Rocco M, Colombo E, and Rizzoni G., "A multidimensional well-to-wheels analysis of passenger vehicles in different regions: Primary energy consumption, $\mathrm{CO} 2$ emissions, and economic cost," Appl Energy, 169:197-209, 2016. doi:10.1016/J.APENERGY.2016.02.039.

[51] Onat NC, Kucukvar M, Tatari O, and Zheng QP., "Combined application of multi-criteria optimization and life-cycle sustainability assessment for optimal distribution of alternative passenger cars in U.S.," J Clean Prod, 112:291-307, 2016. doi:10.1016/J.JCLEPRO.2015.09.021.

[52] Zhao Y, Onat NC, Kucukvar M, and Tatari O., "Carbon and energy footprints of electric delivery trucks: A hybrid multi-regional inputoutput life cycle assessment," Transp Res Part D Transp Environ, 47:195-207, 2016. doi:10.1016/j.trd.2016.05.014.

[53] Onat NC, Gumus S, Kucukvar M, and Tatari O., "Application of the TOPSIS and intuitionistic fuzzy set approaches for ranking the life cycle sustainability performance of alternative vehicle technologies," Sustain Prod Consum, 6, 2016. doi:10.1016/j.spc.2015.12.003.

[54] Bicer Y, and Dincer I., "Comparative life cycle assessment of hydrogen, methanol and electric vehicles from well to wheel," Int J Hydrogen Energy, 42:3767-77, 2017. doi:10.1016/J.IJHYDENE.2016.07.252.

[55] Onat NC, Noori M, Kucukvar M, Zhao Y, Tatari O, and Chester M., "Exploring the suitability of electric vehicles in the United States," Energy, 121:631-42, 2017.

[56] Carnegie Mellon University Green Design Institute, "Economic InputOutput Life Cycle Assessment (EIO-LCA) 2008,” 2008. http://www.eiolca.net/index.html.

[57] National Renewable Energy Laboratory. U.S., "Life Cycle Inventory Database 2013," 2013. http://www.nrel.gov/lci/.

[58] Burnham A, Wang M, and Wu Y., "Development and Applications of GREET 2.7 - The Transportation Vehicle-Cycle Model," Energy, 124, 2006. doi:10.2172/898530.

[59] Hadley W. S, and Tsvetkova A., "Potential Impacts of Plug-in Hybrid Electric Vehicles on Regional Power Generation," Oak Ridge, Tennessee: 2008

[60] The World Energy Outlook, "Water for Energy Is energy becoming a thirstier resource?" 2012.

[61] Gerbens-Leenes PW, Hoekstra AY, and van der Meer T., "The water footprint of energy from biomass: A quantitative assessment and consequences of an increasing share of bio-energy in energy supply," Ecol Econ, 68:1052-60, 2009. doi:10.1016/j.ecolecon.2008.07.013.

[62] Meldrum J, Nettles-Anderson S, Heath G, and Macknick J., "Life cycle water use for electricity generation: a review and harmonization of literature estimates," Environ Res Lett., 8:015031, 2013. doi:10.1088/1748-9326/8/1/015031.

[63] EPA, "Gasoline Emission Factor-Calculations and References," 2013. http://www.epa.gov/cleanenergy/energy-resources/refs.html.

[64] U.S. Environmental Protection Agency Office of Transportation and Air Quality, "Fuel Economy Labeling of Motor Vehicles: Revisions to Improve Calculation of Fuel Economy Estimates," 2006.

[65] Hendrickson CT, Lave LB, and Matthews HS., "Environmental life cycle assessment of goods and services: an input-output approach," Resources for the Future, 2005.

[66] Hawkins TR, Singh B, Majeau-Bettez G, and Strømman AH., "Comparative Environmental Life Cycle Assessment of Conventional and Electric Vehicles," J Ind Ecol, 17:53-64, 2013. doi:10.1111/j.15309290.2012.00532.x. 
[67] Onat NC, Kucukvar M, and Tatari O., "Uncertainty-embedded dynamic life cycle sustainability assessment framework: An ex-ante perspective on the impacts of alternative vehicle options," Energy, 112, 2016. doi:10.1016/j.energy.2016.06.129.

[68] National Household Travel Survey. Online Analysis Tools- Table Designer 2009. http://nhts.ornl.gov/tools.shtml.

[69] EPA., "Clean Energy - eGRID," US Energy Prot Agency, 2009. http://www.epa.gov/cleanenergy/energy-resources/egrid/index.html.

[70] Engholm A, Johansson G, and Persson AÅ., "Life Cycle Assessment: of Solelia Greentech's Photovoltaic BasedCharging Station for Electric Vehicles," 2013.

[71] IPCC Working Group I., "Climate Change 2001: The Scientific Basis. Summary for Policymakers," A Report of Working Group 1. Cambridge, UK, 2001.

[72] Onat NC, Kucukvar M, and Tatari O., "Scope-based carbon footprint analysis of U.S. residential and commercial buildings: An input-output hybrid life cycle assessment approach," Build Environ, 72:53-62, 2014.

[73] Park YS, Egilmez G, and Kucukvar M., "Emergy and end-point impact assessment of agricultural and food production in the United States: A supply chain-linked Ecologically-based Life Cycle Assessment," Ecol Indic., 62:117-37, 2016. doi:10.1016/j.ecolind.2015.11.045.

[74] Kucukvar M, and Samadi H., "Linking National Food Production to Global Supply Chain Impacts for the Energy-Climate Challenge: The Cases of the EU-27 and Turkey," J Clean Prod, 108:395-408, 2015. doi:10.1016/j.jclepro.2015.08.117.

[75] Kucukvar M, Egilmez G, and Tatari O., "Evaluating environmental impacts of alternative construction waste management approaches using supply-chain-linked life-cycle analysis," Waste Manag Res, 32:500-8, 2014. doi:10.1177/0734242X14536457.

[76] Gumus S, Kucukvar M, and Tatari O., "Intuitionistic fuzzy multi-criteria decision making framework based on life cycle environmental, economic and social impacts: The case of U.S. wind energy," Sustain Prod Consum., 8:78-92, 2016. doi:10.1016/j.spc.2016.06.006.

[77] Kucukvar M, Egilmez G, Onat NC, and Samadi H., "A global, scopebased carbon footprint modeling for effective carbon reduction policies: Lessons from the Turkish manufacturing," Sustain Prod Consum, 1, 2015. doi:10.1016/j.spc.2015.05.005.

[78] Kucukvar M, Cansev B, Egilmez G, Onat NC, and Samadi H., "Energyclimate-manufacturing nexus: New insights from the regional and global supply chains of manufacturing industries," Appl Energy, 184:889-904, 2016. doi:10.1016/j.apenergy.2016.03.068.

[79] Toyota, "Toyota Corolla Specifications 2014," 2014. http://www.toyota.com/corolla/\#!/Welcome.

[80] Toyota, "Toyota Prius-HEV Specifications 2014," 2014. http://www.toyota.com/prius/features.html\#!/weights_capacities/1223/1 225/1227/1229.

[81] Nissan, "Nissan Leaf Specifications 2014," 2014. http://www.nissanusa.com/electric-cars/leaf/versions-specs/.

[82] Toyota, Toyota Prius-PHEV Specifications 2014," 2014. http://www.toyota.com/prius-plugin/features.html\#!/mechanical/1235/1237.

[83] Marriott J, and Matthews HS., "Environmental Effects of Interstate Power Trading on Electricity Consumption Mixes," Environ Sci Technol., 39:8584-90, 2005. doi:10.1021/es0506859.

[84] Onat NC, Egilmez G, and Tatari O., "Towards greening the U.S. residential building stock: A system dynamics approach," Build Environ., 78:68-80, 2014. doi:10.1016/j.buildenv.2014.03.030.

[85] Onat NC, Kucukvar M, Halog A, and Cloutier S., "Systems Thinking for Life Cycle Sustainability Assessment: A Review of Recent Developments, Applications, and Future Perspectives," Sustain 2017, Vol 9, 9:706, 2017. doi:10.3390/SU9050706.

[86] Alirezaei M, Onat NC, Tatari O, and Abdel-Aty M., "The Climate Change-Road Safety-Economy Nexus: A System Dynamics Approach to Understanding Complex Interdependencies," Systems, 5:6, 2017.

[87] Kucukvar M, Noori M, Egilmez G, and Tatari O., "Stochastic decision modeling for sustainable pavement designs," Int J Life Cycle Assess, 19:1185-99, 2014. doi:10.1007/s11367-014-0723-4.

[88] Onat NC, Kucukvar M, and Tatari O., "Integrating triple bottom line input-output analysis into life cycle sustainability assessment framework: the case for US buildings," Int J Life Cycle Assess, 19:1488-505, 2014. doi:10.1007/s11367-014-0753-y.

[89] Tatari O, Kucukvar M, and Onat NC., "Towards a Triple Bottom Line Life Cycle Sustainability Assessment of Buildings," Sci. Sustain. Constr. Manuf. Work, Vol. I. Position Pap. Find., pp. 226, 2015. 